\title{
ICT Revolution from Traditional Office to Virtual Office: A Study on Teleworking During the COVID-19 Pandemic
}

\author{
Muddassar SARFRAZ ${ }^{1}$, Larisa IVASCU ${ }^{2,3 *}$, Kausar Fiaz KHAWAJA ${ }^{4}$, \\ Adrian Victor VEVERA ${ }^{5}$, Florin DRAGAN ${ }^{6}$ \\ ${ }^{1}$ College of International Students, Wuxi University, 333 Xishan Avenue, Wuxi, 214105, China \\ muddassar.sarfraz@gmail.com \\ ${ }^{2}$ Management Department, Faculty of Management in Production and Transportation, \\ Politehnica University of Timisoara, 14 Remus Street, Timisoara, 300009, Romania \\ larisa.ivascu@upt.ro (*Corresponding author) \\ ${ }^{3}$ Academy of Romanian Scientists, 3 Ilfov Street, 050044 Bucharest, Romania \\ ${ }^{4}$ Faculty of Management Sciences, International Islamic University, Sector H-10, Islamabad, 44000, Pakistan \\ kausar.khawaja@iiu.edu.pk \\ ${ }^{5}$ National Institute for Research and Development in Informatics, 8-10 Maresal Averescu Avenue, \\ Bucharest, 01145, Romania \\ victor.vevera@ici.ro \\ ${ }^{6}$ Department of Automation and Applied Informatics, Faculty of Automation and Computers, \\ Politehnica University of Timisoara, 14 Remus Street, Timisoara, 300009, Romania \\ florin.dragan@upt.ro
}

\begin{abstract}
The biggest challenge of today's world is to adjust to the rapidly changing environment brought about by the COVID-19 pandemic, where uncertainty and unpredictability have become the norm. The advanced technological tools used during the pandemic have altered communication, employee motivation, and the employees ' desire for personal connectivity. The main objective of this paper is to analyse the effect of professional isolation on the teleworker's job performance, motivation, and turnover intention. This study also considers the moderating role of the access to information and communications technology. In this context, a survey was carried out among the employees from the telecommunications/ IT sector in Islamabad, Lahore and Karachi, Pakistan and 478 complete/usable responses were received and analysed. In this paper, the MACRO PROCESS computational procedure was employed. A confirmatory factor analysis was carried out, along with an analysis on Pearson correlation, internal consistency reliability, discriminant validity of the variables employed in this study, and hierarchical moderated regression analysis with the purpose of testing six hypotheses. The obtained results show that there is a negative relationship between professional isolation and the employees' job performance and motivation. On the other hand, professional isolation is positively associated with turnover intention. To that, professional isolation and the access to communication-enhancing technology (ACET) significantly affect employee job motivation.
\end{abstract}

Keywords: Professional isolation, Job performance, Motivation, Turnover intention, ICT, COVID-19.

\section{Introduction}

The COVID-19 pandemic has forced a large population to work remotely. The temporary shift from the traditional workspace to remote working has triggered significant changes in working patterns, leading to a new layer of complexity (i.e., professional isolation). The transformations related to the COVID-19 pandemic have altered the norms while diminishing the cross-cultural boundaries. The pandemic has pushed businesses and other entities to expand their operations beyond the national borders. This expansion has led to a change in working methods, especially to a flexible schedule and work from home. These changes have also been found in the application areas of communication technology and the use of information (Raišiene et al., 2020). Telework or work from home offers flexibility and independence to employees and the possibility to be close to one's family. At the same time, the impact of employees on the environment is reduced, considering specific aspects of transport. In early 2020, many global companies made it easier for employees to work from home to avoid overcrowding. As a result, employees' interests in teleworking began to grow, and this facility came to be accepted by more and more workers (Nguyen, 2021). Over time, employees began to feel the need to socialize. As a result, employees began to return to work at low rates in some countries, feeling constrained by working from home. However, the fluctuations in COVID-19 outbreaks have made workers switch to working from home again earlier this year, $2021(\mathrm{Li}$ et al., 2020; Pulido-Martos et al., 2021). The Covid-19 period led to millions of workers in the European Union and worldwide working from home. In 2020, approximately $40 \%$ of workers in the EU carried out full-time telework (European Commission, 2020). Teleworking is positively related to firm performance (Sánchez 
et al., 2007). The pandemic has changed the way companies operate, and social distancing can affect employees' motivation levels. Several risks may arise in the organizational activity, which they must adequately manage. Research shows the pandemic has significantly reshaped the global working environment, by influencing individual job performance, motivation, and turnover intention. Based on this, the study shows that the COVID-19 pandemic has led to an increase in employees' performance (Mihalca et al., 2021) and motivation (Palumbo et al., 2021).

The management team has a decisive role in employee performance and the growth of organizations. Management decisions will have consequences on turnover, employee motivation, performance, and communication. Studies show that a period of work from home can have considerable effects on productivity, communication, dynamics, and labor relations (Ruiz-Frutos et al., 2020). In this pandemic context, the present paper investigates the impact of professional isolation on the teleworker's job performance, motivation, and turnover intention. The study also considers the moderating role of access to information communication technology. The remainder of this paper is structured as follows. Section 2 presents the literature review, Section 3 sets forth the employed methodology, and Section 4 presents the results of this study. Finally, Section 5 presents the conclusion of this paper.

\section{Literature Review}

Before the outbreak of COVID-19, different studies revealed a significant reduction in the family-to-work conflict by implementing familyfriendly workplace practices such as flexible working arrangements and onsite childcare (Neal et al., 1993; Daniels et al., 2001). However, as the current pandemic continues to unfold, the conflict between the work and the family sphere has increased tremendously. In addition, the employees are encouraged to work due to the rapid spread of COVID-19 (Petcu et al., 2021). This situation has increased loneliness and social exclusion among employees (Kopp, 2020). The term "Teleworking" refers to the workplace practice strengthening both organizational and employee flexibility. As per definition, Teleworking refers to an organization using information and communication technology to provide access to employees in order for them to carry out labor activities from remote locations
(Nilles, 1998). Various researchers from different schools of thought have presented their empirical findings describing the relationship between teleworking and employee job performance. To demonstrate the significance of prior studies on teleworking, it was found that virtual teams operating online tend to be more productive and efficient at brainstorming than face-to-face teams (DeRosa et al., 2007). However, on the contrary, according to the argument presented by the researchers on individual job performance, virtual teammates tend to miss the creative benefits that can flow from face-to-face interactions (Allen et al., 2015).

\subsection{Professional Isolation and Job Performance}

Professional isolation is defined as a state of mind or belief that keeps an individual away from the workplace (Diekema, 1992). It can also be defined as a feeling of isolation from professional peers, i.e., colleagues. Professional isolation makes teleworkers fear losing the organizational reward as they think staying out of the manager's sight would limit the opportunity for their promotion and career advancement. By contrast, social isolation refers to the employees 'inability to develop informal interactions with their coworkers and friends.

Consequently, due to poor decision-making, professionally isolated teleworkers are rather unable to adopt the appropriate course of action, therefore, they would experience diminished psychological and physical health, which would further reduce the employee job performance. Rook (1984) argues that professionally isolated teleworkers are less likely to understand and interpret the information accurately, which would adversely affect their task performance. However, the study concludes that teleworkers have higher chances for career advancement by demonstrating superior performance. Likewise, most researchers argue that employee productivity and work quality improve when employees work from home. On the other hand, due to increasing professional isolation, it has become difficult for the supervisors to manage and monitor teleworkers' performance (Greer \& Payne, 2014). The implications of artificial intelligence in the commerce sector can help one determine customer needs. To that, there is a direct relationship between gender diversity and a firm`s financial performance. Therefore, 
the findings of Banciu et al. (2013) conclude that employees' work relationships provide the access to detailed knowledge about the tasks, and personalities of co-workers and managers, which may be essential for executing the job well. Bunea \& Dinu (2020) investigated the relationship between the board of directors' characteristics and business operations.

Moreover, the main weakness of electronic communication is that it makes home a boring place to work, as it does not offer any physical separation between work and personal time. This disadvantage creates uncertainty, thus affecting job satisfaction. Perhaps, a decrease in job satisfaction would result in poor job performance (Nisar et al., 2019). Therefore, the current study concludes the following hypothesis:

$\mathrm{H} 1$ : Professional Isolation is negatively related to Job Performance

\subsection{Professional Isolation and Motivation}

A relevant example of professional isolation nowadays is related to is the global COVID-19 Pandemic, which has forced millions of workers worldwide to work from their homes. Numerous studies have explained the impact of professional isolation on employees' motivation. As it was stated, teleworking can provide solid incentives for an individual by fulfilling the employee's needs, such as flexible working hours. This relaxation opportunity boosts employee autonomy and motivation (O’Neil et al., 2009).

Furthermore, Madsen (2003) explains that teleworking is a win-win situation for both the personnel and the organization, making it convincible to reduce costs, motivate workers, and create work-life stability. In the wake of the COVID-19 Pandemic, the environment supporting the fulfilment of individual needs and desires has drastically altered. Consequently, in response to the current Pandemic, the organizations are now supporting their business activities by implementing advanced technology, i.e. teleworking. Nonetheless, these new practices, which involve virtual socialization, develop a sense of solid affiliation among the employees, consequently affecting the worker's motivation. Hence, previous studies concluded the following hypothesis:
$\mathrm{H} 2$ : Professional Isolation is negatively related to Job Motivation

\subsection{Professional Isolation and Turnover Intention}

The employee turnover intention is the employees' voluntary disseverance from employment ties (Izvercian et al., 2016). According to Park \& Jung (2015), employee turnover is an individual's eagerness to leave the organization. There is a positive correlation between turnover intention and work engagement (Xiong \& Wen, 2020).

Due to the immense spread of COVID-19, the entire globe is being hit with unique challenges, making it difficult for organizations to retain their workforce. The results of the study by Kokubun, Ino \& Ishimura (2020) show that companies are trying to establish a strong relationship with their employees by staying resilient. However, most researchers state that teleworking does not always produce a negative outcome. Teleworking serves as an effective management strategy in reducing organization losses, i.e. expenses. Similarly, by gaining financial and productivity advantages, teleworkers can contribute towards organizational productivity and effectiveness (Martin \& MacDonnell, 2012; Banciu et al., 2017). A comprehensive study by Bailey \& Kurland (2002) states that telecommuting enhances job performance by reducing employee turnover.

Gajendran \& Harrison (2007) conducted a detailed meta-analysis of 46 studies and explained that teleworking allows employees to work from home, thereby reducing the turnover intention and the number of days of sick leave. Fonner \& Roloff (2010) suggest that high-intensity teleworkers were found to be more satisfied than the office-based employees, thus gaining substantial benefits from remote working. Hence, the findings of the previous studies concluded the following hypothesis:

H3: Professional Isolation is positively related to turnover intention

\subsection{The Moderating Role of Access to Communication- Enhancing Technology}

The biggest challenge of today's world is to adjust to the rapidly changing environment brought about by COVID-19, where uncertainty 
and unpredictability have become the norm. The COVID-19 had made the adoption of technology a business necessity. In relation to that, the COVID-19 had posed social and psychological implications while highlighting the utilization of digital technology and information service as a novel way of predicting employment opportunities (Baert et al., 2020). The advanced technological tools used during the Pandemic have altered communication, employee motivation, and their desire for personal connectivity (Banciu et al., 2020; Pérez et al., 2004). The digital era has brought about a booming evolution leading to the development of instant communication networks. Currently, digital communication involves highly functional telecommunication networks for ensuring social congruence. Undoubtedly, the global access to telecommunication technologies has benefited its users such as employees, clients, and the company, which led to a change from physical interactions to online connectivity. Felstead \& Henseke (2017) claim that the progressive advancement of IT boosts employee morale by nourishing work-life harmony. On the other hand, individuals with weak interpersonal ties tend to leave the organization quickly (Dinu et al., 2020). For explaining this notion, the study reveals that ICT interactive functionality has shaped the workplace structure while constantly improving job performance (Tanko \& Isyaku, 2020). Likewise, Davies (2021) also shows that the ICT-based technologies used during the pandemic have improved the workers' performance.

The new advancement in information and telecommunication technologies is an asset to the workplace as it enables the employee to work outside the traditional workplace setting. Above all, these advanced technological attributes contribute to employee satisfaction, which is essential for preserving the workers, and directly related to job turnover. However, new IT developments have made workers feel that their job performance is undoubtedly affected by remote working (Major et al., 2008). Morikawa (2020) explains that the unexpected evolution of COVID-19 has turned traditional business practices upside down. As a result, many organizations have begun to break the workplace's physical boundaries to establish a flexible and diverse communication network. However, as the Pandemic continues to evolve, practical and innovative virtual communication tools need to be enhanced in order for workers to perform their obligations safely and effectively (Cybersecurity \& Infrastructure Security Agency, 2020). In addition to this, Sein (2020) suggests that the specific nature of the COVID-19 Pandemic requires companies to establish a strong coordination between IT infrastructure, their people, and work practices in order to facilitate international collaborations. However, the new state-of-the-art technological tools can benefit from combating the effects of COVID-19 (Sein, 2020). Therefore, based on literature, the following hypotheses were concluded:

H4: Access to communication technology has a moderating role between professional isolation and employees' job performance;

H5: Access to communication technology has a moderating role between professional isolation and employees' job motivation;

H6: Access to communication technology has a moderating role between professional isolation and employee turnover intention.

The variables selected for this study are presented in Figure 1.

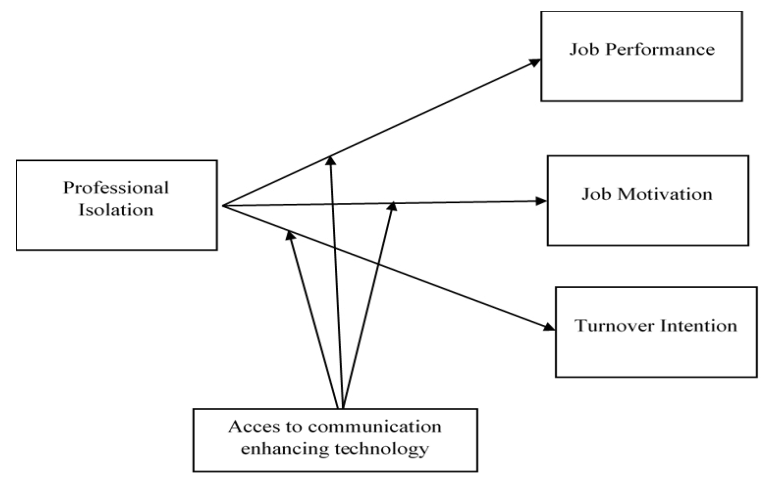

Figure 1. The theoretical framework

\section{Methodology}

A quantitative research was conducted. Data was collected at two time points from employees of the telecommunication/IT companies in Islamabad/ Lahore/Karachi, Pakistan. A gap of one month between each measurement point, i.e. time- 1 and time-2, was kept. Participants responded with regard to independent and moderating variables at time- 1 and dependent variables, namely: job performance, turnover intentions, and employees' motivation at time-2. To keep track of whether 
the participants responded at both time points, participants were requested to mention their employee ID/contact number, which could have helped the researchers match their responses at time- 1 and time- 2 .

Initially, 600 teleworkers were requested to participate in the survey, from which 478 complete/usable responses were received, with a response rate of $80 \%$. They were asked about their age, gender, qualification, work experience, independent and moderating variables. After a period of 1 month, the 478 participants who responded at time-1 were contacted again and requested to participate in the time- 2 survey; however, this time 430 complete responses were received. The overall response rate was $72 \%$.

\subsection{Measures}

The seven-item scale of Golden, Veiga \& Dino (2008) was employed to assess Professional Isolation. The five-point Likert Scale was used for measuring professional isolation, ranging from "strongly disagree" to "strongly agree". To measure Access to communication-enhancing technology the four-item scale suggested by Golden, Veiga \& Dino (2008) was used. The four-item scale of Wayne \& Liden (1995) was used in this study for measuring employees' job performance. Supervisors were also requested to rate teleworkers' (subordinates') job performance, and it was measured using a fivepoint Likert scale from 0 (not effective) to 4 (very effective). The two-item scale of Schaubroeck, Cotton \& Jennings (1989) was used for measuring employees' turnover intention and it was also measured using a five-point Likert scale ranging from "strongly disagree" to "strongly agree".
Further on, the job motivation scale of Mahaney \& Lederer (2006) was implemented in this study. The scale consists of 16 items, and these were measured by using a five-point Likert scale. After applying a data cleaning and screening procedure, i.e. missing data analysis and outlier detection technique, confirmatory factor analysis (CFA) was conducted to check the validity of the results. The results of the five-factor model are Comparative Fit Index $(\mathrm{CFI})=0.935$; Goodnessof-Fit Index $(\mathrm{GFI})=0.867$; Adjusted Goodnessof-Fit Index $(\mathrm{AGFI})=0.814$; Normed Fit Index $(\mathrm{NFI})=0.845$, and Root Mean Square Error of Approximation $($ RMSEA) $=0.05$, that is, they are within the acceptable range in comparison with the results of the one-factor model, namely: $\mathrm{CFI}=0.750 ; \mathrm{GFI}=0.647$; $\mathrm{AGFI}=0.630$; $\mathrm{NFI}=$ 0.660 and RMSEA $=1.20$, which confirms the discriminant validity of the variables employed in this study.

\section{Results}

Table 1 illustrates descriptive statistics, mean, standard deviation, correlation among variables, internal consistency reliability (Cronbach alpha), and composite reliability, and average variance extracted, which are within range as it was suggested by Hair et al. (2010) and Lowry \& Gaskin (2014).

Professional isolation is significantly associated with job satisfaction $(\mathrm{R}=-0.48, \mathrm{p}<.05)$, turnover intention $(\mathrm{R}=-0.46, \mathrm{p}<.05)$, job motivation $(\mathrm{R}=-0.39, \mathrm{p}<.05)$ and access to communicationenhancing technology $(R=0.53, p<.05)$.

In this study, the MACRO PROCESS computational procedure was employed

Table 1. Mean, Standard Deviation, Internal Consistency Reliability, Composite Validity, Average Variance Extracted, and Correlation

\begin{tabular}{|c|c|c|c|c|c|c|c|c|c|c|}
\hline & Mean & SD & ICR & CR & AVE & $\mathbf{1}$ & $\mathbf{2}$ & $\mathbf{3}$ & $\mathbf{4}$ & $\mathbf{5}$ \\
\hline Professional Isolation & 3.87 & 1.77 & 0.820 & 0.87 & 0.51 & $(0.71)$ & & & & \\
\hline Job Satisfaction & 3.95 & 1.98 & 0.835 & 0.79 & 0.52 & $-0.48^{* *}$ & $(0.72)$ & & & \\
\hline Turnover intention & 2.98 & 1.93 & 0.842 & 0.81 & 0.54 & $0.46^{* *}$ & $-0.30^{* *}$ & $(0.74)$ & & \\
\hline Job Motivation & 4.39 & 1.76 & 0.950 & 0.92 & 0.50 & $-0.39^{* *}$ & $0.43^{*}$ & $-0.34^{*}$ & $(0.70)$ & \\
\hline $\begin{array}{c}\text { Access to } \\
\begin{array}{c}\text { communication } \\
\text { enhancing technology }\end{array}\end{array}$ & 3.72 & 1.85 & 0.808 & 0.78 & 0.58 & $0.53^{*}$ & $0.27^{*}$ & $-0.56^{*}$ & $0.48^{* *}$ & $(0.76)$ \\
\hline
\end{tabular}

Note: Sample Size = 430, $S D=$ Standard deviation, ICR = Internal Consistency Reliability (Cronbach's alpha), $C R=$ Composite Reliability, $A V E=$ Average Variance Extracted, Significance Level $={ }^{*} p<.05, * * p<.01, * * *^{*}<.001$ 
(Model 1 developed by Hayes (2017)) for testing the moderation analysis. Table 2,3 and 4 illustrate $(\mathrm{H} 1),(\mathrm{H} 2),(\mathrm{H} 3)$, and moderation analysis. Hypothesis (H1) points to a negative relationship between job performance and professional isolation. There is a negative relationship between professional isolation and job motivation according to (H2) and a positive relationship between the former and turnover intentions, according to (H3). The results revealed that there are significant relationships among these hypotheses with a standardized beta coefficient value $(\beta)$, where $\beta=-0.327, p<0.01, \beta=-0.582$, $\mathrm{p}<0.05$ and $\beta=0.268, \mathrm{p}<0.05$, respectively. Hence hypotheses 1, 2, 3 were statistically proved.

Table 2 represents the interaction term related to professional isolation and ACET for job performance $(\mathrm{H} 4)$ was found to be significant with $(\beta=-0.215, p<0.05)$. Moreover, the conditional direct effects illustrated in Table 2 show the relationship between professional isolation and employees' job performance weakens when teleworkers have higher ACET $(\beta=-0.458, \mathrm{p}<.05)$. Thus, hypothesis (4) is proved. Figure 2 shows the graphical representation of the moderating effect of ACET on employees' job performance.

Table 2. Hierarchical Moderated Regression Analysis for ACET between Professional Isolation and Job Performance

\begin{tabular}{|c|c|c|c|c|c|c|}
\hline \multirow[t]{2}{*}{ Predictors } & \multicolumn{6}{|c|}{ Job Satisfaction } \\
\hline & $\mathrm{R}$ & $\mathrm{R}^{2}$ & Estimate & SE & LLCI & ULCI \\
\hline Step 1 & $0.46 * * *$ & 0.22 & & & & \\
\hline Constant & & & $6.733 * * *$ & 1.745 & 1.135 & 3.568 \\
\hline PI & & & $-0.327 * *$ & 0.498 & 0.325 & 1.265 \\
\hline ACET & & & $0.204 * * *$ & 0.426 & 5.658 & 4.568 \\
\hline Step 2 & $\Delta \mathrm{R}^{2}$ & 0.19 & & & & \\
\hline PI x ACET & & & $-0.215^{* *}$ & 0.325 & 1.758 & 2.554 \\
\hline \multicolumn{7}{|c|}{ Conditional Direct Effects of X on Y for Values of Moderator (i.e. ACET) } \\
\hline \multirow[t]{2}{*}{ Moderator } & & & \multicolumn{4}{|c|}{ Job Performance } \\
\hline & & & Effect & Boot SE & LLCI & ULCI \\
\hline ACET -1SD (-.185) & & & $-0.458 * * *$ & 0.029 & 0.297 & 0.325 \\
\hline ACET mean $(0.00)$ & & & $-0.409 * * *$ & 0.032 & 0.145 & 0.225 \\
\hline $\mathrm{ACET}+1 \mathrm{SD}(1.85)$ & & & $-0.365^{*}$ & 0.035 & 0.025 & 0.110 \\
\hline
\end{tabular}

Note: $P I=$ Professional Isolation, ACET = Access to communication-enhancing technology, Correlation coefficient $=R$, Coefficient of Determination $=R 2$, Change in Coefficient of Determination $=\Delta \mathrm{R}^{2}$, Standard Error $(S E), L L=$ Lower Limit, $C I=$ Confidence Interval, $U L=$ Upper Limit, ${ }^{*} p<.05,{ }^{*} *_{p}<.01, *_{*}^{*} p<.001$

Table 3. Hierarchical Moderated Regression Analysis for ACET between Professional Isolation and Job Motivation

\begin{tabular}{|c|c|c|c|c|c|c|}
\hline \multirow[t]{2}{*}{ Predictors } & \multicolumn{6}{|c|}{ Job Motivation } \\
\hline & $\mathrm{R}$ & $\mathrm{R}^{2}$ & Estimate & $\mathrm{SE}$ & LLCI & ULCI \\
\hline Step 1 & $0.55^{*}$ & 0.35 & & & & \\
\hline Constant & & & $2.334 * *$ & 3.548 & 5.256 & 11.856 \\
\hline PI & & & $-0.582 *$ & 0.756 & 0.014 & 0.754 \\
\hline ACET & & & $0.365^{*}$ & .556 & 1.745 & 3.254 \\
\hline Step 2 & $\Delta \mathrm{R}^{2}$ & 0.30 & & & & \\
\hline PI x ACET & & & $-0.124 * *$ & 0.220 & 0.965 & 2.015 \\
\hline \multicolumn{7}{|c|}{ Conditional Direct Effects of X on Y for Values of Moderator (i.e. ACET) } \\
\hline \multirow[t]{2}{*}{ Moderator } & & & \multicolumn{4}{|c|}{ Job Motivation } \\
\hline & & & Effect & Boot SE & LLCI & ULCI \\
\hline ACET -1SD (-.185) & & & $-0.356^{* *}$ & 0.235 & 0.032 & 0.124 \\
\hline ACET mean $(0.00)$ & & & $-0.301 *$ & 0.324 & 0.112 & 0.325 \\
\hline $\mathrm{ACET}+1 \mathrm{SD}(1.85)$ & & & $-0.288^{*}$ & 0.125 & 0.425 & 0.564 \\
\hline
\end{tabular}


Table 4. Hierarchical Moderated Regression Analysis for ACET between Professional Isolation and Turnover Intention

\begin{tabular}{|c|c|c|c|c|c|c|}
\hline \multirow[t]{2}{*}{ Predictors } & \multicolumn{6}{|c|}{ Turnover Intention } \\
\hline & $\mathrm{R}$ & $\mathrm{R}^{2}$ & Estimate & SE & LLCI & ULCI \\
\hline Step1 & $0.37 *$ & 0.28 & & & & \\
\hline Constant & & & $4.485 * *$ & 1.635 & 7.896 & 9.256 \\
\hline PI & & & $0.268^{*}$ & 0.895 & 0.248 & 0.658 \\
\hline ACET & & & $-0.146^{* *}$ & 0.354 & -1.245 & -0.554 \\
\hline Step 2 & $\Delta \mathrm{R}^{2}$ & 0.26 & & & & \\
\hline PI x ACET & & & $0.216^{*}$ & 0.196 & 0.245 & 5.478 \\
\hline \multicolumn{7}{|c|}{ Conditional Direct Effects of X on Y for Values of Moderator (i.e. ACET) } \\
\hline \multirow[t]{2}{*}{ Moderator } & & & \multicolumn{4}{|c|}{ Turnover Intention } \\
\hline & & & Effect & Boot SE & LLCI & ULCI \\
\hline ACET -1SD (-.185) & & & $0.235 * * *$ & 0.399 & 0.480 & 0.582 \\
\hline ACET mean $(0.00)$ & & & $0.201 *$ & 0.312 & 0.356 & 0.425 \\
\hline $\mathrm{ACET}+1 \mathrm{SD}(1.85)$ & & & $0.145^{*}$ & -0.458 & 0.025 & 0.149 \\
\hline
\end{tabular}

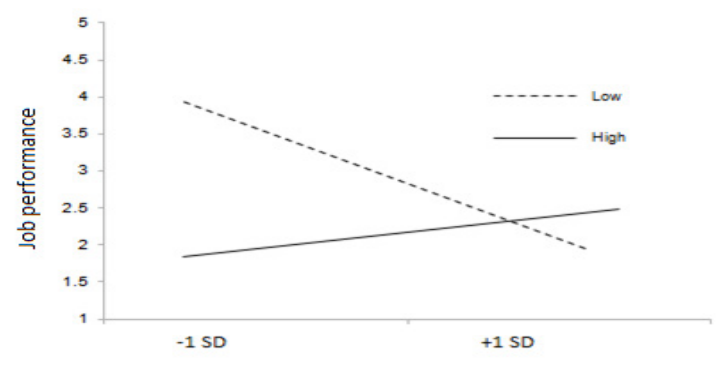

Figure 2. Moderating effect of ACET on employees` Job Performance

Table 3 also shows the results for hypothesis (H5). According to hypothesis (5), the interaction term related to professional isolation and ACET for job motivation (H5) was found to be significant with $(\beta=-0.124, p<0.05)$. Moreover, the conditional direct effects illustrated in Table 3 show that the relationship between professional isolation and job motivation weakens when teleworkers have higher ACET $(\beta=-0.356, p<.05$, see Figure 3$)$. Thus, hypothesis (5) is proved.

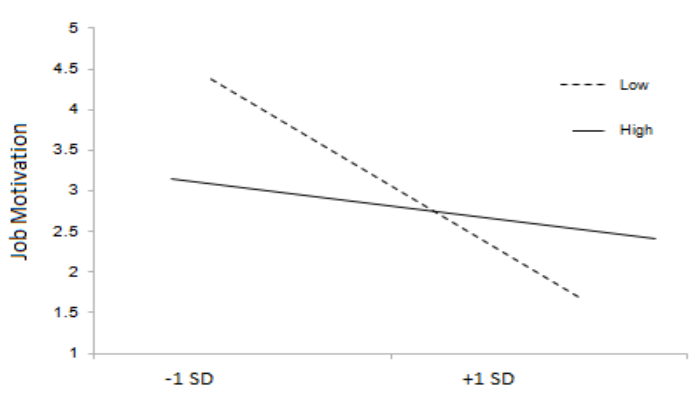

Figure 3. Moderating effect of ACET on Job Motivation
Similarly, the interaction term related to professional isolation and ACET for turnover intention (H6) was found to be significant with $(\beta=0.216, p<0.05)$. Moreover, the conditional direct effects illustrated in Table 4 show the connection between professional isolation and employees' turnover intention. The relationship weakens when teleworkers have higher ACET $(\beta=0.235, \mathrm{p}<.001)$. Thus, hypothesis $(6)$ is proved. Figure 4 represents the moderating effect of ACET on turnover intension.

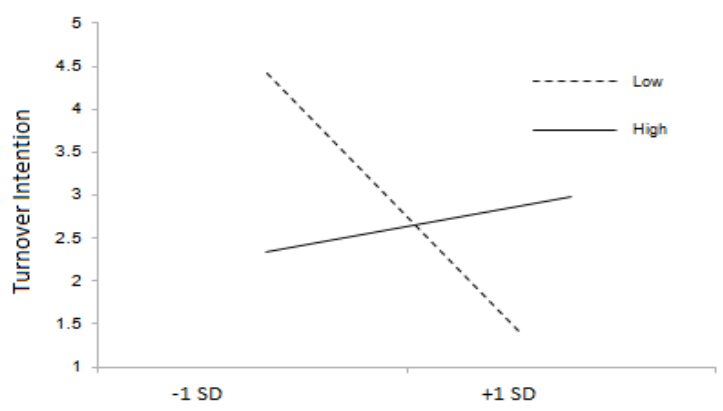

Figure 4. Moderating effect of ACET on Turnover Intention

\section{Conclusion}

The current situation provides deep insight into how organizations are adopting teleworking for constructing effective communication networks. Hence, the literature concludes that the COVID-19 pandemic has made remote working become a new reality. The advanced technological tools which came to be used intensively as a result of the COVID-19 Pandemic have drastically altered 
the business communication structure. Indeed, ICT-based technologies have gained considerable attention during the pandemic. As a result, businesses should adopt ICT-based technologies for achieving favourable outcomes.

The COVID-19 pandemic has generated changes in the way companies operate, and social distancing can affect the employees' levels of motivation, job performance, and mental wellbeing. Teleworkers are facing several challenges during the global pandemic. The organizations are reducing onsite staff and encouraging employees to work online. The employees have been professionally isolated. The role of information and technology has increased. This study analysed the effect of professional isolation on the employees' motivation, job performance, and turnover intentions. It revealed that professional isolation had affected employees' job performance in the telecommunication and information technology industry. In this context, the employee's motivation level is low which also led to a lower job performance. On the other hand, employees' turnover intention got higher because of professional isolation. Communicationenhancing technology is playing a moderating role with regard to professional isolation and job performance. If organizations provide better information communication technology services to their employees, then job performance can be increased. Future studies could consider other different moderating variables such as COVID-19 Vaccines and satisfaction with organization COVID-19 responses? Authors may also carry out cross-national studies while implementing the theoretical model proposed in this paper.

\section{REFERENCES}

Allen, T. D., Golden, T. D. \& Shockley, K. M. (2015). How effective is telecommuting? Assessing the status of our scientific findings, Psychological Science in the Public Interest, 16(2), 40-68. DOI: $10.1177 / 1529100615593273$

Baert, S., Lippens, L., Moens, E., Weytjens, J. \& Sterkens, P. (2020). The Covid-19 Crisis and Telework: A Research Survey on Experiences, Expectations and Hopes, IZA Discussion Paper No. 13229. Available at SSRN: <https://ssrn.com/abstract=3596696>.

Bailey, D. E. \& Kurland, N. (2002). A review of telework research: Findings, new directions, and lessons for the study of modern work, Journal of Organizational Behavior, 23(4), 383-400.

Banciu, D., Cîrnu, C. E., Anghel, E. \& Neagoe, A. (2013). Digital Single Market: Cross-Border eGoverment Services, JADLET - Journal of Advanced Distributed Learning Technology, 1(3-4), 61-65.

Banciu, D., Petre, I. \& Sandu, I. (2017). Security challenges of .RO domains at the core of information society, Bulletin of the Transilvania University of Brasov, 10(59), no. 1, Series III, 193-202.

Banciu, D., Rădoi, M. \& Belloiu, S. (2020). Information Security Awareness in Romanian Public Administration: An Exploratory Case Study, Studies in Informatics and Control, 29(1), 121-129. DOI: 10.24846/v29i1y202012

Bunea, M. \& Dinu, V. (2020). The relationship between the boards characteristics and the risk management of the Romanian banking sector, Journal of Business Economics and Management, 21(5), 1248-1268. DOI: 10.3846/jbem.2020.12694
Cybersecurity \& Infrastructure Security Agency releases version 3.0 of guidance on Essential critical Infrastructure workers During COVID-19 (2020). Available at: <https://www.cisa.gov/news/2020/04/17/ cisa-releases-version-30-guidance-essential-criticalinfrastructure-workers- during >, last accessed: March $15,2021$.

Daniels, K., Lamond, D. \& Standen, P. (2001). Teleworking: Frameworks for organizational research, Journal of Management Studies, 38(8), 1151-1185.

Davies, A. (2021). COVID-19 and ICT-Supported Remote Working: Opportunities for Rural Economies, World, 2(1), 139-152.

DeRosa, D. M., Smith, C. L. \& Hantula, D. A. (2007). The medium matters: Mining the long-promised merit of group interaction in creative idea generation tasks in a meta-analysis of the electronic group brainstorming literature, Computers in Human Behavior, 23(3), 1549-1581. DOI: 10.1016/j.chb.2005.07.003

Diekema, D. A. (1992). Aloneness and social form, Symbolic interaction, 15(4), 481-500. DOI: 10.1525/ si.1992.15.4.481

Dinu, V., Virlanuta, F. O., Zamfir, C., Stanciu, S., Guven, E. T. A. \& Yatbaz, A. (2020). Measuring the Impact of Social Progress on The Recycling Rate at European Level By Using Econometric Models, Transformations in Business \& Economics, 19(2A), 535-550.

European Commission, Report - Telework in the EU before and after the COVID-19: where we were, where we head to. Available at: <https://ec.europa.eu/jrc/ sites/jrcsh/files/jrc120945_policy_brief__covid_and telework final.pdf $>$, last accessed: March $15,20 \overline{2} 1$. 
Felstead, A. \& Henseke, G. (2017). Assessing the growth of remote working and its consequences for effort, well-being and work-life balance, New Technology, Work and Employment, 32(3), 195-212.

Fonner, K. L. \& Roloff, M. E. (2010). Why teleworkers are more satisfied with their jobs than are office-based workers: When less contact is beneficial, Journal of Applied Communication Research, 38(4), 336-361. DOI: $10.1080 / 00909882.2010 .513998$

Gajendran, R. S. \& Harrison, D. A. (2007). The good, the bad, and the unknown about telecommuting: metaanalysis of psychological mediators and individua consequences, Journal of Applied Psychology, 92(6), 1524-1541.

Golden, T. D., Veiga, J. F. \& Dino, R. N. (2008). The impact of professional isolation on teleworker job performance and turnover intentions: Does time spent teleworking, interacting face-to-face, or having access to communication-enhancing technology matter? Journal of Applied Psychology, 93(6), 1412-1421. DOI: $10.1037 / \mathrm{a} 0012722$

Greer, T. W. \& Payne, S. C. (2014). Overcoming telework challenges: Outcomes of successful telework strategies, The Psychologist-Manager Journal, 17(2), 87.

Hair, J. F., Anderson, R. E., Babin, B. J. \& Black, W. C. (2010). Multivariate data analysis: A global perspective, 7 th ed. Pearson Prentice Hall.

Hayes, A. F. (2017). Introduction to mediation, moderation, and conditional process analysis: $A$ regression-based approach. Guilford publications.

Izvercian, M., Potra, S \& Ivascu, L. (2016). Job satisfaction variables: A grounded theory approach, Procedia - Social and Behavioral Sciences, 221, 8694. DOI: $10.1016 /$ j.sbspro.2016.05.093

Kokubun, K., Ino, Y. \& Ishimura, K. (2020). Social capital and resilience make an employee cooperate for coronavirus measures and lower his/her turnover intention. Available at: <https://arxiv.org/ abs/2007.07963>, last accessed: March 06, 2021.

Kopp, D. (2020). Loneliness Is a Health Hazard. Available at: <https:/www.wsj.com/articles/ loneliness-is-a-health-hazard-too-11584906625>, last accessed: March 20, 2021.

Li, K., Liu, X., Mai, F. \& Zhang, T. (2020). The role of corporate culture in bad times: Evidence from the COVID-19 pandemic, Journal of Financial and Quantitative Analysis, 1-68. DOI: 10.2139/ ssrn.3632395

Lowry, P. B. \& Gaskin, J. (2014). Partial least squares (PLS) structural equation modeling (SEM) for building and testing behavioral causal theory: When to choose it and how to use it, IEEE Transactions on Professional Communication, 57(2), 123-146.
Mahaney, R. C. \& Lederer, A. L. (2006). The effect of intrinsic and extrinsic rewards for developers on information systems project success, Project Management Journal, 37(4), 42-54.

Major, D. A., Verive, J. M. \& Joice, W. (2008). Telework as a dependent care solution: Examining current practice to improve telework management strategies, The Psychologist-Manager Journal, 11(1), $65-91$.

Martin, B. H. \& MacDonnell, R. (2012). Is telework effective for organizations?, Management Research Review, 35, 602-616.

Mihalca, L., Irimiaș, T. \& Brendea, G. (2021). Teleworking During the COVID-19 Pandemic: Determining Factors of Perceived Work Productivity, Job Performance, and Satisfaction, Amfiteatru Economic Journal, 23(58), 620.

Morikawa, M. (2020). COVID-19, teleworking, and productivity. Available at: $<\mathrm{https}$ //voxeu.org/ article/covid-19-teleworking-and-productivity $>$, last accessed: October 7, 2020.

Neal, M. B., Chapman, N. J., Ingersoll-Dayton, B. \& Emlen, A. C. (1993). Balancing work and caregiving for children, adults, and elders. SAGE Publications.

Nguyen, M. H. (2021). Factors influencing homebased telework in Hanoi (Vietnam) during and after the COVID-19 era, Transportation, 48, 3207-3238. DOI: $10.1007 / \mathrm{s} 11116-021-10169-5$

Nilles, J. M. (1994). Making telecommuting happen: A guide for telemanagers and telecommuters. Van Nostrand Reinhold, New York, USA, John Wiley \& Sons.

Nisar, T. M., Prabhakar, G. \& Strakova, L. (2019). Social media information benefits, knowledge management and smart organizations, Journal of Business Research, 94, 264-272.

O`Neill, T. A., Hambley, L. A., Greidanus, N. S., MacDonnell, R. \& Kline, T. J. (2009). Predicting teleworker success: An exploration of personality, motivational, situational, and job characteristics, New Technology Work and Employment, 24(2), 144-162.

Palumbo, R., Flamini, G., Gnan, L., Pellegrini, M. M., Petrolo, D.\& Fakhar Manesh, M. (2021), Disentangling the implications of teleworking on work-life balance: a serial mediation analysis through motivation and satisfaction, Journal of Organizational Effectiveness: People and Performance, Vol. ahead-of-print No. ahead-of-print. DOI: 10.1108/JOEPP-08-2020-0156

Park, I.-J. \& Jung, H. (2015). Relationships among future time perspective, career and organizational commitment, occupational self-efficacy, and turnover intention, Social Behavior and Personality, 43(9), 1547-1562. 
Pérez, M. P., Sánchez, A. M., Carnicer, P. D. \& Jiménez, M. J. (2004). A technology acceptance model of innovation adoption: the case of teleworking, European Journal of Innovation Management, 7(4), 280-291.

Petcu, M. A., Sobolevschi-David, M. I., Anica-Popa, A., Curea, S. C., Motofei, C. \& Popescu, A. M. (2021). Multidimensional Assessment of Job Satisfaction in Telework Conditions. Case Study: Romania in the COVID-19 Pandemic, Sustainability, 13(16), 8965.

Pulido-Martos, M., Cortés-Denia, D. \& Lopez-Zafra, E. (2021). Teleworking in Times of COVID-19: Effects on the Acquisition of Personal Resources, Frontiers in Psychology, 12(1), 2485.

Raišienè, A. G., Rapuano, V., Varkulevičiūtè, K. \& Stachová, K. (2020). Working from Home - Who is Happy? A Survey of Lithuania's employees during the COVID-19 quarantine period, Sustainability, $12(13), 5332$.

Rook, K. S. (1984). Research on social support, loneliness, and social isolation: Toward an integration, Review of Personality \& Social Psychology, 5, 239-264.

Ruiz-Frutos, C., Ortega-Moreno, M., Dias, A., Bernardes, J. M., García-Iglesias, J. J. \& GómezSalgado, J. (2020). Information on COVID-19 and psychological distress in a sample of non-health workers during the pandemic period, International Journal of Environmental Research and Public Health, 17(19), 6982.
Sánchez, A. M., Pérez, M. P., Carnicer, P. D \& Jiménez, M. J (2007). Teleworking and workplace flexibility: a study of impact on firm performance, Personnel Review, 36(1), 42-64.

Schaubroeck, J., Cotton, J. L. \& Jennings, K. R. (1989). Antecedents and consequences of role stress: A covariance structure analysis, Journal of Organizational Behavior, 10(1), 35-58.

Sein, M. K. (2020). The serendipitous impact of COVID-19 pandemic: A rare opportunity for research and practice, International Journal of Information Management, 55, 102164.

Tanko, A. A \& Isyaku, A. R. (2020). Effect of Information and Communication Technology on the Performance of Estate Surveyors and Valuers during COVID-19 pandemic in federal capital territory Abuja - Nigeria, International Journal of Social Sciences and Management Review, 3(4), 277-287. DOI: 10.37602/ IJSSMR.2020.3419

Wayne, S. J. \& Liden, R. C. (1995). Effects of impression management on performance ratings: A longitudinal study, Academy of Management Journal, $38(1), 232-260$.

Xiong, R. \& Wen, Y. (2020). Employees' turnover intention and behavioral outcomes: The role of work engagement, Social Behavior and Personality: An International Journal, 48(1), 1-7. 